\title{
Immunolocalization of Gastrin-Releasing Peptide in the Bovine Uterus and Placenta
}

\author{
Teguh BUDIPITOJO'), Shigenori MATSUZAKI ${ }^{2)}$, Maria Bella C. CRUZANA ${ }^{1)}$, Emmanuel T. BALTAZAR ${ }^{1)}$, \\ Eiichi HONDO $^{3)}$, Sumiyati SUNARYO ${ }^{4}$, Nobuo KITAMURA ${ }^{1)}$ and Junzo YAMADA ${ }^{1)}$ \\ ${ }^{1)}$ Department of Veterinary Anatomy, Obihiro University of Agriculture and Veterinary Medicine, Obihiro 080-8555, ${ }^{2)} \mathrm{Hokkaido}$ \\ Livestock Improvement Association Inc., Shimizu, Hokkaido 089-0103, ${ }^{3)}$ Department of Veterinary Anatomy, Faculty of Agriculture, \\ Yamaguchi University, Yamaguchi 753-8515, Japan and ${ }^{4)}$ Department of Veterinary Anatomy, Faculty of Veterinary Medicine, Gadjah \\ Mada University, Yogyakarta 55281, Indonesia
}

(Received 23 June 2000/Accepted 6 September 2000)

ABSTRACT. Gastrin-releasing peptide (GRP), a mammalian homologue of amphibian bombesin, has been suggested to be a novel regulatory peptide in the reproductive tract during pregnancy. In this study, the localization of GRP in the bovine uterus and placenta was demonstrated by immunohistochemistry. Uterine and placental samples were collected from nonpregnant and pregnant specimens, respectively. Tissue sampling was done from the caruncle and intercaruncle of the uterus, and from the placentome (caruncle and cotyledon) and intercotyledon of the placenta. In all the tissues examined, GRP was detected although its immunoreactivity was observed at various degrees. In the uterus, moderate immunoreactivity for GRP was observed in the uterine gland epithelial cells. In the placenta, strong immunoreactivity for GRP was demonstrated in the uterine gland epithelial cells; moderate in superficial epithelial cells; and weak in the trophoblasts, trophoblastic giant cells and cryptal epithelial hybrid cells. In both nonpregnant and pregnant animals, GRP was immunolocalized in the uterine gland secretions and was found predominantly in the supranuclear region of the uterine gland epithelial cells. These findings may suggest that GRP is secreted into the uterine lumen and regulates the intrauterine environment of both the nonpregnant and pregnant bovine by exocrine, autocrine and/or paracrine manner.

KEY WORDS: bovine, GRP, immunohistochemistry, placenta, uterus.

J. Vet. Med. Sci. 63(1): 11-15, 2001

Gastrin-releasing peptide (GRP), a mammalian homologue of amphibian bombesin, was first isolated from porcine gastric and intestinal tissue extracts [12]. As the name denotes, the peptide stimulates gastrin secretion [13]. It also regulates the release of most gastrointestinal hormones [11]. In the female reproductive tract, it exhibits various physiological effects, such as control of epithelial ion transport in the endometrium [10] and modulation of uterine contraction [1]. Furthermore, it serves as a circulating hormone in fetal and uterine development [4], as a mitogenic agent for numerous tissues including the uterus [5], and as an autocrine and paracrine regulatory peptide in the endometrium [16].

GRP is distributed in the brain [3, 15], lung [9] and genital organs [2, 6, 17-19]. The distribution of GRP immunoreactivity in the female genital organs, however, varies among animal species, and even within the same species depending on the reproductive status, i.e., whether nonpregnant or pregnant. In the human, GRP immunoreactivity has been detected only during pregnancy, predominantly in the trophoblasts of placental villi, extravillous trophoblasts and amniotic epithelial cells [19]. In the ovine, a small ruminant, it has been reported both in nonpregnant and pregnant animals, predominantly in the uterine gland epithelial cells and the tissue surrounding the glands at days 20 and 140 of pregnancy, and only at day 16 of the estrous cycle of nonpregnant animals [18]. GRP immunoreactivity has also been observed in the superficial epithelial cells of the intercotyledonary endometrium during pregnancy but not after parturition [2]. In the large ruminant, no report has so far been published on the localization of GRP in the female reproductive organ.
The present immunohistochemical study was, therefore, conducted to investigate the distribution of GRP immunoreactivity in the bovine uterus and placenta.

\section{MATERIALS AND METHODS}

Placentae of sixteen pregnant bovine (1 to 8 months of pregnancy), and uteri of 6 nonpregnant bovine were used in the study (Table 1). The samples were obtained from a local slaughterhouse. The tissue samples were collected from the caruncle and intercaruncle of the uterus, and from the placentome (comprising the caruncle and cotyledon) and intercotyledon of the placenta. After fixation in Bouin's fluid for 24 $\mathrm{hr}$, the tissue samples were dehydrated in ethanol, cleared in xylene and embedded in paraffin. Sections were cut serially at 3 and $5 \mu \mathrm{m}$ in thickness. For histological and histochemi-

Table 1. Summary of the cows used in the study

\begin{tabular}{cc}
\hline Reproductive status & Number of animals \\
\hline Pregnant (month of gestation, CRL*) & \\
1 month (CRL $3.8 \mathrm{~cm}, 4.9 \mathrm{~cm})$ & 2 \\
2 months (CRL $8.1 \mathrm{~cm}, 8.2 \mathrm{~cm}, 9.5 \mathrm{~cm}$ ) & 3 \\
3 months (CRL $12 \mathrm{~cm}, 16 \mathrm{~cm}$ ) & 2 \\
4 months (CRL $25 \mathrm{~cm}, 28.5 \mathrm{~cm}$ ) & 2 \\
5 months (CRL $32 \mathrm{~cm}, 37 \mathrm{~cm})$ & 2 \\
6 months (CRL $41 \mathrm{~cm}, 45 \mathrm{~cm})$ & 2 \\
7 months (CRL $50 \mathrm{~cm})$ & 1 \\
8 months (CRL $60 \mathrm{~cm}, 80 \mathrm{~cm})$ & 2 \\
Nonpregnant & \\
Adult & 6 \\
\hline
\end{tabular}

*CRL $=$ crown-rump-length 
cal evaluations, sections were stained with hematoxylin and eosin, Azan, and periodic acid Schiff.

For immunohistochemical staining, avidin-biotin-peroxidase complex (ABC) method was employed. Tissue sections were first deparaffinized in xylene and then rehydrated in descending series of ethanol concentration. After washing in $0.01 \mathrm{M}$ phosphate-buffered saline, sections were incubated with $0.3 \% \mathrm{H}_{2} \mathrm{O}_{2}$ in methanol for 15 min to block endogenous peroxidase activity; overnight at $4{ }^{\circ} \mathrm{C}$ with anti-porcine GRP raised in the rabbit (R-6902, donated by Dr. N. Yanaihara, Yanaihara Institute, Shizuoka, Japan) as the primary antibody; and with biotinylated anti-rabbit IgG raised in the goat (1:200, BA-1,000, Vector Laboratories Inc., Burlingame, U.S.A.) as the secondary antibody for $45 \mathrm{~min}$ at room temperature. Then the sections were incubated with ABC (Vectastain Elite $^{\circledR}$ ABC Kit, PK-6100, Vector Laboratories Inc.) for $30 \mathrm{~min}$ at room temperature. To obtain good contrast in the photomicrography, the primary antibody was used at 1:9,000 dilution for uterine gland epithelial cells, and at 1:3,000 for placental trophoblastic giant cells, cryptal epithelial hybrid cells and superficial epithelial cells. These optimal dilutions were determined on the basis of the results of dilution test conducted up to 1:48,000. To prevent nonspecific staining, sections were incubated with normal goat serum before incubation with the primary antibody. The immunoreactive sites were visualized by the use of Tris- $\mathrm{HCl}$ buffer ( $\mathrm{pH} 7.4$ ) containing $0.02 \%$ 3,3'-diaminobenzidine tetrahydrochloride and $0.03 \% \mathrm{H}_{2} \mathrm{O}_{2}$. Some sections were counterstained lightly with Mayer's hematoxylin. Stained sections were examined with Nikon conventional microscope, and photomicrographs were taken with Nikon microscope (Nikon, Tokyo, Japan) equipped with Nomarski differential interference contrast optics.

The negative controls conducted to assess the specificity of the antibody were: 1) immunoabsorption of the primary antibody with a synthetic GRP $(0.0001-100 \mu \mathrm{g} / \mathrm{ml}$, R5553, Bachem, Torrance, CA, U.S.A.) prior to incubation of the section, and 2) replacement of the primary antibody with normal rabbit serum.

\section{RESULTS}

The present study demonstrated gastrin-releasing peptide (GRP) immunoreactivity in the bovine uterus and placenta. Table 2 summarizes the results of the semiquantitative evaluation of the intensity of immunoreactivity for GRP in the uterine and placental tissues. The distribution and intensity of GRP immunoreactivity varied between the nonpregnant and pregnant bovine, and also among the different anatomical parts of the uterus and placenta.

In the nonpregnant, GRP immunoreactivity was detected only in the uterine gland epithelial cells of both the caruncle and intercaruncle of the uterus, and not in the superficial epithelial cells (Fig. 1A). In the uterine gland epithelial cells, GRP immunoreactivity was detected in all endometrial compartments. In these cells, GRP immunoreactivity was mod-
Table 2. Semiquantitative evaluation of the intensity of immunoreactivity of gastrin-releasing peptide cells in the bovine uterus and placenta

\begin{tabular}{lc}
\hline \multicolumn{1}{c}{ Cells } & Intensity of immunoreactivity \\
\hline Uterus (Nonpregnant) & - \\
Caruncle & ++ \\
Superficial epithelial cells & \\
Uterine gland epithelial cells & - \\
Intercaruncle & ++ \\
Superficial epithelial cells & \\
Uterine gland epithelial cells & \\
Placenta (Pregnant) & ++ \\
Caruncle of the placentome & +++ \\
Superficial epithelial cells & + \\
Uterine gland epithelial cells & \\
Cryptal epithelial hybrid cells & + \\
Cotyledon of the placentome & + \\
Trophoblasts & \\
Trophoblastic giant cells & - \\
Intercotyledon & +++ \\
Superficial epithelial cells & \\
Uterine gland epithelial cells & \\
\hline
\end{tabular}

The uterine gland secretions and nerve fibers showed strong and weak immunoreactivity, respectively.

+++: strong, ++: moderate, +: weak, -: negative.

erate and predominantly localized in the supranuclear region (Fig. 1A). The secretions of the uterine glands also showed immunoreactivity for GRP, although its intensity was weak (Fig. 1B).

In pregnant specimens, GRP was immunolocalized in the uterine gland epithelial cells of the placentome caruncle and intercotyledon, superficial epithelial and cryptal epithelial hybrid cells of the placentome caruncle, and trophoblasts and trophoblastic giant cells (TGC) of the cotyledon. The distribution of the GRP-immunoreactive cells and the intensity of immunoreactivity for GRP in each anatomical part examined were consistent throughout the pregnancy period. The most intense GRP immunoreactivity was observed in the uterine gland epithelial cells of the caruncle and intercotyledon (Fig. 1C). In these cells, GRP immunoreactivity was concentrated in the supranuclear region of the cells (Fig. 1C). In the uterine gland secretions, the intensity was strong (Fig. 1C) to moderate. Many of the superficial epithelial cells of the placentome caruncle showed moderate immunoreactivity for GRP (Fig. 2A). The immunoreactivity was mainly localized in the supranuclear cytoplasm of the superficial epithelial cells. Weak GRP immnunoreactivity was shown in the trophoblasts, TGC (Fig. 2C), and cryptal epithelial hybrid cells (Fig. 2D).

In both nonpregnant and pregnant animals, immunoreactivity for GRP was also detected in the nerve fibers located in the endometrium (Fig. 1B) and myometrium. However, it was not demonstrated in other tissues examined in the study.

In all cases, no immunoreactivity for GRP was observed in the negative controls (Figs. 1D, 2B). 

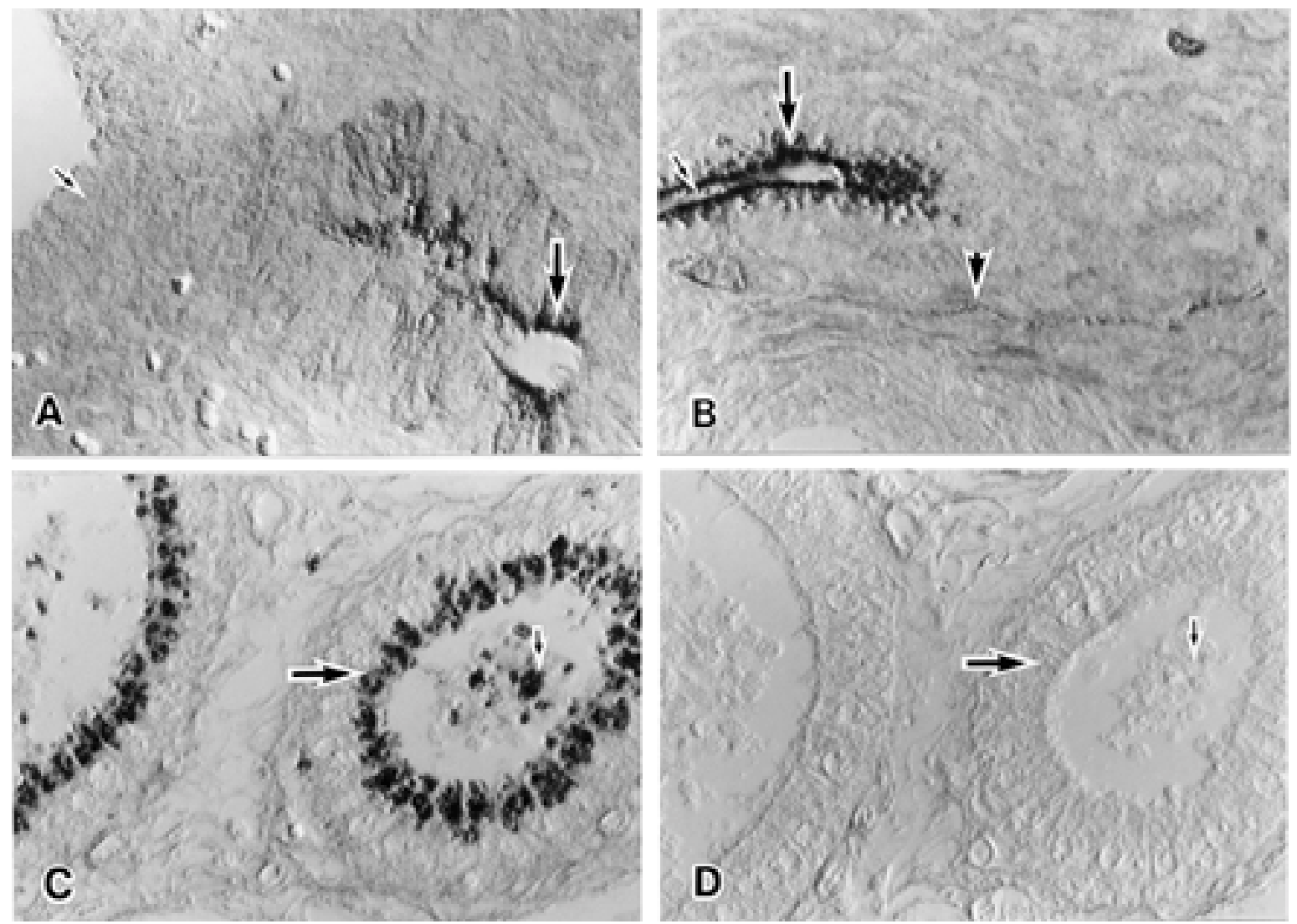

Fig. 1. Immunohistochemical staining for gastrin-releasing peptide (GRP) in the bovine uterus. (A) A nonpregnant bovine uterus showing the moderate immunoreactivity in the supranuclear region of the glandular epithelium (large arrow) and negative immunoreactivity in the superficial epithelium (small arrow). (B) A nonpregnant bovine uterus showing the moderate immunoreactivity in the glandular epithelium (large long arrow) and nerve fibers (large short arrow), and weak immunoreactivity in the secretory product (small arrow). (C) Uterine gland of 4-month-pregnant animal showing strong immunoreactivity in the supranuclear region of epithelium (large arrow) and strong immunoreactivity in the secretory product (small arrow). (D) Negative immunoreactivity in the preabsorption control of serial section of $(C)$. A-D $\times 400$; Nomarski differential interference contrast.

\section{DISCUSSION}

The present study demonstrated gastrin-releasing peptide (GRP) immunoreactivity in the bovine uterus and placenta. As aforementioned, GRP has been immunolocalized in the uteri and placentae of human [19] and ovine [2, 18]. In contrast to the human, GRP immunoreactivity was observed in the ovine not only in the pregnant placenta but also in the nonpregnant uterus. Although the present finding agrees with that of the ovine, the present results revealed variations in the distribution of GRP immunoreactivity in the bovine from that in the ovine. During pregnancy, the GRP-immunoreactive superficial epithelial cells were observed only in the placentome caruncle of bovine, while in the ovine, they have been detected only in the intercotyledonary endometrium [2]. Furthermore, the GRP-immunoreactive trophoblasts and trophoblastic giant cells were present in the bovine but not in the ovine $[2,18]$. These discrepancies in the distribution of GRP immunoreactivity may be related to species difference.
In the present study, the intensity of immunoreactivity for GRP was stronger in the pregnant than in the nonpregnant bovine. In the ovine, GRP immunoreactivity has been reported in the superficial epithelial cells during pregnancy but not after parturition [2]. Furthermore, GRP-immunoreactive uterine gland epithelial cells have been observed at days 20 and 140 of pregnancy, and only at day 16 of the estrous cycle of nonpregnant ovine [18]. Northern blot analysis has also revealed that the level of GRP mRNA found in the uterus at full term is much higher than those in the uteri of nonpregnant ovine $[2,18]$ and human [17]. Therefore, it seems that GRP plays a more active regulatory role in the female reproductive tract in pregnant than in nonpregnant animals.

The presence of GRP immunoreactivity has been reported in the uterine gland epithelial cells of the pregnant and nonpregnant ovine uteri [18]. In the present study, GRP immunoreactivity was observed in all tissue samples examined, predominantly in the uterine gland epithelial cells of both nonpregnant and pregnant animals. The predominance of 

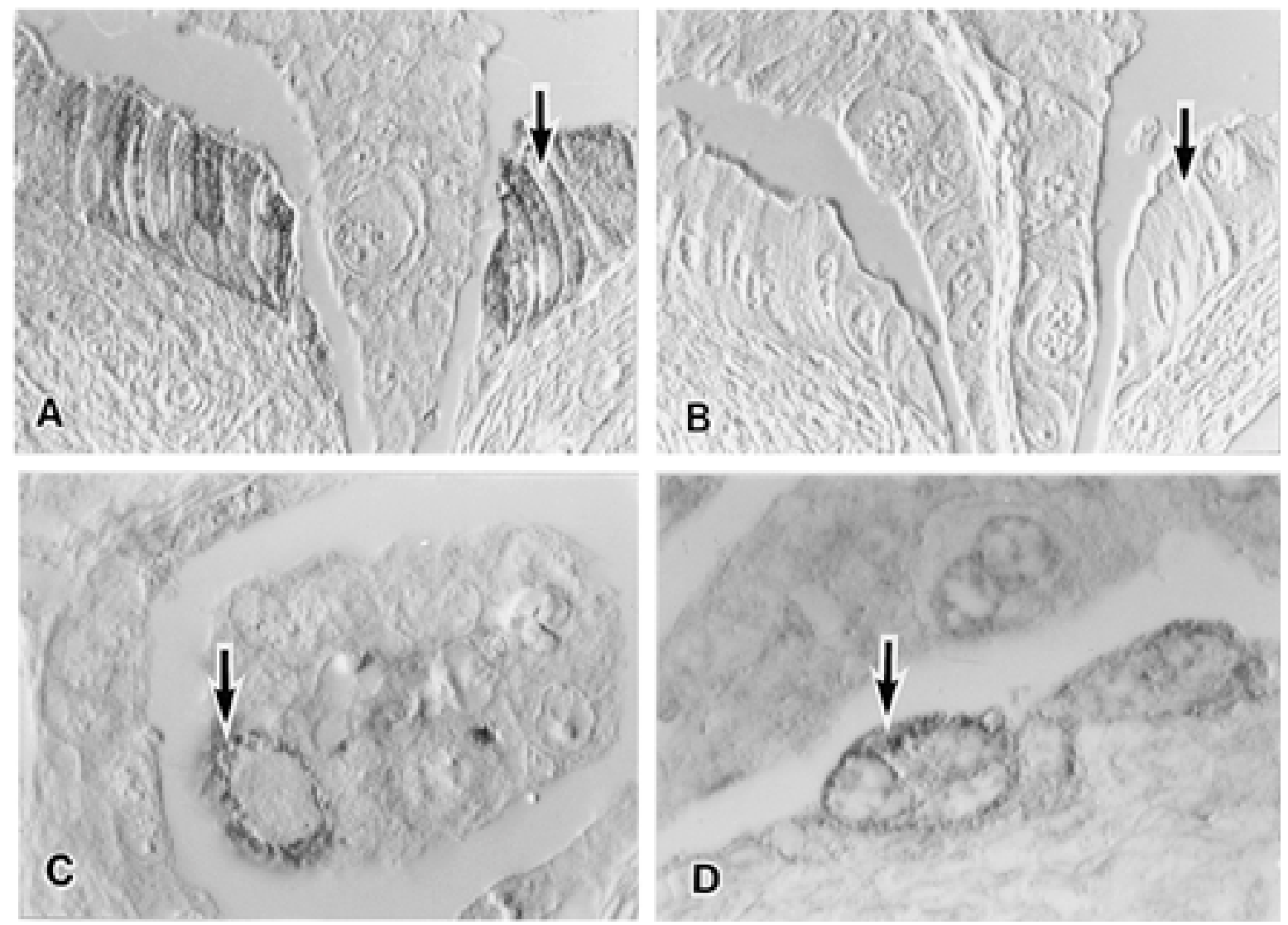

Fig. 2. Immunohistochemical staining for gastrin-releasing peptide (GRP) in the bovine placentome of 7-month-pregnant animal. (A) Positive immunoreactivity in the uterine superficial epithelial cells (arrow) covering the placentome caruncle. (B) Negative immunoreactivity in the preabsorption control (arrow). A and B are serial sections. (C) Weak immunoreactivity in the cotyledonary trophoblastic giant cell (arrow). (D) Weak immunoreactivity in the cryptal epithelial hybrid cell (arrow). D is counterstained lightly by Mayer's hematoxylin. A-D × 875; Nomarski differential interference contrast.

GRP immunoreactivity in the uterine gland epithelial cells of both ovine and bovine, and the presence of GRP mRNA expression in the ovine endometrium [2,18] may suggest that uterine gland epithelial cells are the primary source of GRP in the ruminant uterus. Furthermore, the occurrence of GRP in the uterine glands of nonpregnant ruminant may be dependent on the estrous cycle.

In the present study, GRP immunoreactivity was detected in the supranuclear region of the uterine gland epithelial cells and in the uterine gland secretions of both the pregnant and nonpregnant animals. This may suggest that GRP is secreted into the uterine lumen and may directly influence the intrauterine environment of both the pregnant and nonpregnant bovine by exocrine manner. At the light microscopic level, GRP immunoreactivities were observed to have a granular appearance. However, it is not yet clear whether they are stored in the secretory granules. Further study by electron microscopy is necessary to clear this matter.

The extravillous trophoblasts (intermediate cytotrophoblasts) have been found in certain cases to form binucleated cells in human fetal membrane at full term, and have shown intense positive cytoplasmic staining for GRP [19]. In the present study, trophoblasts and both mononucleated and multinucleated trophoblastic giant cells (TGC) showed GRP immunoreactivity. Previously, it has been reported that TGC secrete substances vital to embryonic survival during pregnancy [7]. In this context, GRP in the trophoblasts and TGC of both the human and bovine may be considered as one of the secretory products necessary for embryonic development. Its mode of action may be via autocrine and/or paracrine mechanisms.

The present study showed GRP immunoreactivity in the cryptal epithelial hybrid cells (trinucleated feto-maternal hybrid cells). These cells are usually formed from the migration and fusion of TGC with the uterine epithelium during pregnancy [8]. This migration process provides a unique delivery system from trophoblastic to maternal tissues [14]. In this study, the presence of GRP immunoreactivity both in TGC and cryptal epithelium hybrid cell may suggest that GRP has a role in the TGC migration and formation of fetomaternal hybrid cell.

Modification of the lining of the superficial epithelial cells 
of the placentome caruncle has been considered as one of the important and typical histological changes of successful implantation in the cotyledonary placenta [14]. Such modification in the superficial epithelial cell lining was also observed in the bovine. The present immunolocalization of GRP in the superficial epithelial cells may imply that GRP might be involved in the implantation process.

GRP mRNA has been expressed in the uterine gland epithelial cells of the ovine uterus and placenta $[2,18]$. Considering that the ovine and bovine are closely related, both being ruminants, the present immunopositive staining may suggest that GRP might also be endogenously synthesized in the cell.

In conclusion, we suggest that GRP plays an important role in the regulation of the intrauterine environment of both nonpregnant and pregnant bovine by exocrine, autocrine and/ or paracrine manners.

ACKNOWLEDGEMENT. The authors are deeply indebted to Dr. N. Yanaihara, Yanaihara Institute, Shizuoka, Japan, for the generous gift of antisera.

\section{REFERENCES}

1. Amiot, F., Leiber, D., Marc, S. and Harbon, S. 1993. GRP-preferring bombesin receptors increase generation of inositol phosphates and tension in rat myometrium. Am. J. Physiol. 265: C1579-1587.

2. Fraser, M., McDonald, T. J., Spindel, E. R., Fahy, M., Hill, D. and Challis, J. R. G. 1985. Gastrin-releasing peptide is produced in the pregnant ovine uterus. Endocrinology 135: 2440-2445.

3. Ghatei, M. A., Bloom, S. R., Langevin, H., McGregor, G. P., Lee, Y. C., Andrian, T. E., O'Shaughnessy, D. J., Blank, M. A. and Uttenthal, L. O. 1984. Regional distribution of bombesin and seven other regulatory peptides in the human brain. Brain Res. 293: 101-109.

4. Giraud, A., Parker, L., Taupin, D., Hardy, K. and Shulkes, A. 1993. Mammalian bombesin as a hormone in ovine pregnancy: ontogeny, origin, and molecular forms. Am. J. Physiol. 263: E866-873.

5. Giraud, A., Whitley, J., Shulkes, A. and Parker, L. 1996. The pregnant ovine endometrium constitutively expresses and secretes a highly stable bombesin-like peptide, which shares Cterminal sequence but differs structurally from gastrin-releasing peptide. Biochim. Biophys. Acta 1296: 189-197.

6. Happola, O. and Lakomy, M. 1989. Immunohistochemical localization of calcitonin gene-related peptide and bombesin/ gastrin-releasing peptide in nerve fibers of the rat, guinea pig and pig female genital organs. Histochemistry 92: 211-218.

7. Hoffman, L. H. and Wooding, F. B. P. 1993. Giant and binucle- ate trophoblast cells of mammals. J. Exp. Zool. 266: 559-577.

8. Klisch, K., Pfarrer, C., Schuler, G., Hoffmann, B. and Leiser, R. 1999. Tripolar acytokinetic mitosis and formation of feto-maternal syncytia in the bovine placentome: different modes of generation of multinuclear cells. Anat. Embryol. 200: 229-237.

9. Maruno, K., Yamaguchi, K., Abe, K., Suzuki, M., Saijo, N., Mishima, Y., Yanaihara, N. and Shimosato, Y. 1989. Immunoreactive gastrin-releasing peptide as a specific tumor marker in patient with small cell lung carcinoma. Cancer Res. 49: 629632.

10. Matthews, C. J., Redfern, C. P., Thomas, E. J. and Hirst, B. H. 1993. Bombesin and gastrin-releasing peptide stimulate electronic ion transport in cultured human endometrial epithelial cell layers. Exp. Physiol. 78: 715-718.

11. McDonald, T. J. 1988. The gastrin-releasing polypeptide. In: Advances in Metabolic Disorder, vol 11 (Mutt, V. ed.), Academic Press Inc., San Diego.

12. McDonald, T. J., Nilsson, G., Vagne, M., Ghatei, M., Bloom, S. R. and Mutt, V. 1978. A gastrin releasing peptide from the porcine nonantral gastric tissue. Gut 19: 767-774.

13. McDonald, T. J., Jorvall, H., Nilsson, G., Vagne, M., Ghatei, M., Bloom, S. R. and Mutt, V. 1979. Characterization of gastrinreleasing peptide from porcine non-antral gastric tissue. Biochem. Biophys. Res. Commun. 90: 227-233.

14. Rodriguez, I., Jimenez, C. and Hernandez, A. 1999. A microscopical study of uterine lining modification, binucleate cell numbers and trophoblastic development, at day 14, 20 and 24 of gestation in single and multiple pregnancies in sheep. Small Rum. Res. 33: 163-168.

15. Sunday, M. E., Kaplan, L. M., Motoyama, E., Chin, W. W. and Spindel, E. R. 1988. Gastrin-releasing peptide (mammalian bombesin) gene expression in health and disease. Lab. Invest. 59: 5-24.

16. Vetter, A. E. and O'Grady, S. M. 1997. Mechanisms of electrolyte transport across the endometrium. II. Regulation by GRP and substance P. Am. J. Physiol. 273: C67-76.

17. Whitley, J. C., Giraud, A. S. and Shulkes, A. 1996. Expression of gastrin-releasing peptide (GRP) and GRP receptors in the pregnant human uterus at term. J. Clin. Endocrinol. Metab. 81: 3944-3950.

18. Whitley, J. C., Shulkes, A., Salamonsen, L. A., Volgiagis, D., Familari, M. and Giraud, A. S. 1998. Temporal expression and cellular localization of a gastrin-releasing peptide-related gene in ovine uterus during the estrous cycle and pregnancy. J. Endocrinol. 157: 139-148.

19. Xiao, Q., Han, X., Challis, J. R., Hill, D. J., Spindel, E. R., Prasad, C. J., Akagi, K. and McDonald, T. J. 1996. Gastrinreleasing peptide-like immunoreactivity is present in human maternal and fetal placental membranes. J. Clin. Endocrinol. Metab. 81: 3766-3773. 